\title{
Long-Term Effectiveness of Liraglutide for Treatment of Type 2 Diabetes in a Real-Life Setting: A 24-Month, Multicenter, Non-interventional, Retrospective Study
}

\author{
Annunziata Lapolla - Cesare Berra - Massimo Boemi • Antonio Carlo Bossi • Riccardo Candido • \\ Graziano Di Cianni · Simona Frontoni · Stefano Genovese · Paola Ponzani • \\ Vincenzo Provenzano · Giuseppina T. Russo · Luigi Sciangula · Natalino Simioni • \\ Cristiano Bette $\cdot$ Antonio Nicolucci (D) On behalf of the NN2211-4118 Study Group
}

Received: November 2, 2017 / Published online: December 21, 2017

(c) The Author(s) 2017. This article is an open access publication

\section{ABSTRACT}

Introduction: The aim of the study was to evaluate whether the reduction in glycated hemoglobin (HbA1c) observed in clinical trials with liraglutide in type 2 diabetes (T2D) could be attained in routine clinical practice.

Enhanced content To view enhanced content for this article go to http://www.medengine.com/Redeem/ 5DFCF0605568025C.

Electronic supplementary material The online version of this article (https://doi.org/10.1007/s12325017-0652-2) contains supplementary material, which is available to authorized users.

A. Lapolla

Department of Medicine, University of Padua, Padua, Italy

C. Berra

Humanitas Research Hospital, Rozzano, MI, Italy

M. Boemi

IRCCS INRCA, Ancona, Italy

A. C. Bossi

ASST Bergamo Ovest, Treviglio, BG, Italy

R. Candido

Azienda Sanitaria Universitaria Integrata di Trieste,

Trieste, Italy

G. Di Cianni

Ospedale di Livorno, Livorno, Italy
Methods: ReaL was a multicenter, non-interventional, observational, retrospective, longitudinal study on the effectiveness of liraglutide, a human glucagon-like peptide- 1 analog, in individuals with T2D treated in daily practice in Italy. Between 26 March and 16 November 2015 , data were taken from clinical records of patients aged $\geq 18$ years with treatment followup data of up to 24 months and who received their first prescription of liraglutide in 2011.

Results: A total of 1723 patients were included in the analysis. At baseline, mean age was 58.9 years, duration of diabetes was 9.6 years, and $\mathrm{HbA} 1 \mathrm{c}$ was $8.3 \%$. At 12 months, $36.1 \%$ of patients were prescribed the maximum $1.8 \mathrm{mg}$ dose; 43.5\% [95\% confidence interval (CI): 40.9;

\section{S. Frontoni}

Department of Systems Medicine, University Tor

Vergata, SG Calibita Fatebenefratelli, Rome, Italy

S. Genovese

IRCCS Centro Cardiologico Monzino, Milan, Italy

P. Ponzani

Ospedale La Colletta, ASL3 Genovese, Arenzano, Italy

\section{Provenzano}

Centro Regionale di Riferimento Diabetologia ed Impianto Microinfusori Sicilia, Partinico, Palermo, Italy

G. T. Russo

Department of Clinical and Experimental Medicine, University of Messina, Messina, Italy 
46.2] of patients attained the primary outcome of a reduction in $\mathrm{HbA} 1 \mathrm{c}$ of $\geq 1 \%$ point at 12 months. At 24 months, $40.9 \%$ (95\% CI 38.1; 43.7) of patients had attained the HbA1c target of $\leq 7 \%$. Additionally, body weight significantly decreased by $3.4 \mathrm{~kg}$ (95\% CI - 3.6; - 3.1, $p<0.0001$ ).

Conclusion: In this observational study conducted in routine clinical practice for up to 2 years, treatment with liraglutide improved HbA1c and reduced body weight in a similar fashion to that observed under randomized clinical trial conditions. The data support the use of liraglutide as an effective treatment for T2D in clinical practice.

Funding: Novo Nordisk S.p.A.

Trial Registration: ClinicalTrials.gov identifier, NCT02255266.

Keywords: Clinical practice; Diabetes; Effectiveness; Glycemic control; Italy; Liraglutide

\section{INTRODUCTION}

The American Diabetes Association (ADA)/European Association for the Study of Diabetes (EASD) position statement emphasized the importance of an individualized glycemic target, as well as an individualized approach to diabetes therapy, based on a variety of patient- and disease-specific factors [1, 2]. Particularly, since overweight and hypertension are highly prevalent in individuals with type 2 diabetes (T2D) [3, 4], an optimal diabetes therapy would not only provide improved

\footnotetext{
L. Sciangula

IRCCS Multimedica-Ospedale di Castellanza, Varese, Italy

N. Simioni

Presidio Ospedaliero di Cittadella, Cittadella, Padua, Italy

C. Bette

Novo Nordisk Spa, Rome, Italy

A. Nicolucci $(\square)$

CORESEARCH-Center for Outcomes Research and Clinical Epidemiology, Pescara, Italy

e-mail: nicolucci@coresearch.it
}

glycemic control but also address other associated comorbidities of T2D. Glucagon-like peptide-1 (GLP-1) receptor agonists have been shown to improve glycemic control and reduce body weight in individuals with T2D [5]. They are recommended as a second-line therapy when diet, exercise and metformin do not provide adequate glycemic control, or as an add-on treatment with sulfonylureas, thiazolidinedione, sodium-glucose cotransporter 2 inhibitor (SGLT2i) or insulin [6] in circumstances where metformin is contraindicated or not tolerated [7].

The efficacy and safety of liraglutide, a human GLP-1 analog, have been demonstrated in the Liraglutide Effect and Action in Diabetes (LEAD) study program of randomized controlled trials [8-13]. Additionally, the LEADER trial reported cardiovascular benefits with liraglutide when used in individuals with T2D at increased risk of cardiovascular disease [14]. Following the regulatory approval of liraglutide, providing real-world evidence for the effectiveness and safety of liraglutide under routine clinical practice conditions is an important step in ensuring appropriate use of the drug in daily practice and confirming the clinical benefits/ risks expected, based on the approved label.

The effectiveness of liraglutide under these conditions has been observed in several European countries, including Italy. However, these studies were limited by either a short follow-up period or suboptimal sample size [15]. Therefore, the overall aim of the ReaL study (NCT02255266) was to retrospectively evaluate the long-term effectiveness of liraglutide in routine clinical practice in Italy. The primary objective of the study was to evaluate whether the reduction in glycated hemoglobin (HbA1c) observed in clinical trials could be attained in patients with T2D routinely managed in outpatient clinics. Secondary objectives included evaluation of the attainment of beneficial effects on body weight, lipid profile, and blood pressure, under the same conditions.

\section{METHODS}

ReaL was a multicenter, non-interventional, observational, retrospective, longitudinal study 
on the effectiveness of liraglutide in outpatients with T2D, treated in daily practice in 45 diabetes clinics in Italy. Patients aged $\geq 18$ years (as per the Victoza ${ }^{\circledR}$ summary of product characteristics [6]) were eligible if they were diagnosed with T2D and received their first prescription of liraglutide in 2011. No exclusion criteria were set and treatment discontinuation during the 24-month study period did not represent a reason for exclusion.

A total of 1788 patient records were extracted from an electronic clinical record (ECR) system widely used for the routine management of patients with T2D in diabetes centers across Italy between 26 March and 16 November 2015. Data were extracted at first prescription of liraglutide (baseline) and after approximately 4, 12 and 24 months of treatment, as recommended by the Italian Standards of Diabetes Care [16] and reported on web-based case report forms. Patient records were obtained from the ECR system on a consecutive basis to minimize the risk of bias.

The primary endpoint was the proportion of patients with an HbA1c reduction $\geq 1 \%$ point after 12 months of treatment. Secondary endpoints included the proportion of patients with an $\mathrm{HbA} 1 \mathrm{c}$ reduction $\geq 1 \%$ point after 4 and 24 months, proportion of patients with a body weight reduction $\geq 3 \%$ and composite endpoint of the two after 4, 12 and 24 months. Additionally, the proportion of patients attaining the ADA/EASD HbA1c target of $\leq 7 \%$ after 4,12 and 24 months was recorded. Continuous secondary endpoints included the change in HbA1c, body weight, blood pressure and lipid profile from baseline to 24 months and the proportion of patients discontinuing treatment for any reason at 4, 12 and 24 months.

\section{Statistical Analysis}

Baseline characteristics are presented as mean \pm standard deviation (SD). For continuous outcomes, data presented are derived from the intention-to-treat (ITT) population, comprised of all patients who received their first prescription of liraglutide in 2011 irrespective of interruption before 24 months. Data were analyzed with hierarchical linear models to assess trends over time. Within-patient correlations and unequal time points were accounted for, using an unstructured correlation type linear model, and changes from baseline were presented as estimated treatment difference (ETD) and 95\% confidence intervals (CI). For categorical endpoints, data were analyzed using a general linear model, post hoc test contrasts were assessed at each time point, and data were expressed as frequencies and percentages with 95\% CI. Missing data and the risk of bias from discontinuation of treatment were accounted for by using longitudinal models. All analyses were performed at the $5 \%$ level of significance. A sample size estimate of 1574 patients was based on $50 \%$ of the subjects maintaining an HbA1c reduction of $\geq 1 \%$ point after 12 months. Statistical analyses were performed using SAS v9.4 (SAS Institute, Cary, NC). All procedures followed were in accordance with the ethical standards of the responsible committee on human experimentation (institutional and national) and with the Helsinki Declaration of 1964, as revised in 2013. Informed consent was obtained from all patients before being included in the study.

\section{RESULTS}

\section{Baseline Characteristics and Subject Disposition}

The results presented reflect the data available as of 31 December 2015. Overall, 1788 patients were extracted from the ECR system; 65 patients were excluded from the analysis, leaving 1723 patients at baseline $(45.1 \%$, female; $54.9 \%$, male). Of the 65 excluded patient records, 56 were omitted owing to the absence of clinical data on the ECR, 6 patients did not give informed consent for the use of their information, and 3 had initiated liraglutide prior to 2011. The numbers of patients with available data at the 4-, 12- and 24-month follow-up were 1499, 1413 and 1217, respectively (Table 1).

Baseline characteristics are presented in Table 2. Mean age was 58.9 years, and mean duration of diabetes was 9.6 years. Mean HbA1c 
Table 1 Proportion of patient records with available data at each study visit

\begin{tabular}{lllll}
\hline Variable & Baseline & $\mathbf{4}$ months & $\mathbf{1 2}$ months & 24 months \\
\hline Group size (N) & 1723 & 1499 & 1413 & 1217 \\
HbAlc (\%) & 95.4 & 96.7 & 97.5 & 97.7 \\
Fasting plasma glucose (\%) & 93.1 & 94.5 & 94.2 & 95.0 \\
Weight (\%) & 95.9 & 97.0 & 95.8 & 95.4 \\
BMI (\%) & 94.5 & 95.9 & 94.8 & 94.5 \\
Waist circumference (\%) & 67.1 & 68.5 & 70.5 & 67.2 \\
Systolic blood pressure (\%) & 81.7 & 80.7 & 80.3 & 80.2 \\
Diastolic blood pressure (\%) & 81.6 & 80.8 & 80.1 & 80.2 \\
Total cholesterol (\%) & 72.3 & 65.5 & 70.6 & 73.1 \\
HDL cholesterol (\%) & 69.8 & 64.5 & 69.2 & 70.8 \\
LDL cholesterol (\%) & 55.3 & 51.4 & 56.3 & 57.4 \\
Triglycerides (\%) & 71.4 & 65.4 & 69.0 & 72.6 \\
Albuminuria (\%) & 31.7 & 32.3 & 34.4 & 35.3 \\
Liraglutide dosage (\%) & 88.5 & 90.0 & 92.0 & 92.4 \\
\hline
\end{tabular}

$B M I$ body mass index, $H b A l c$ glycated hemoglobin, $H D L$ high-density lipoprotein, $L D L$ low-density lipoprotein

at baseline was $8.3 \%$, and mean fasting plasma glucose (FPG) was $171.8 \mathrm{mg} / \mathrm{dl}$. Mean baseline body mass index (BMI), weight and waist circumference were $35.6 \mathrm{~kg} / \mathrm{m}^{2}, 99.6 \mathrm{~kg}$ and $115.5 \mathrm{~cm}$, respectively. Mean estimated glomerular filtration rate at baseline was $85.0 \mathrm{ml} / \mathrm{min} / 1.73 \mathrm{~m}^{2}$. Data for diabetic complications showed that $13.1 \%$ and $1.9 \%$ of patients presented with a personal history of coronary heart disease and stroke, respectively. Peripheral vascular disease was present in $6.7 \%$ of patients, while diabetic retinopathy and sensory motor neuropathy were present in $18.5 \%$ and $13.5 \%$ of patients, respectively.

\section{Liraglutide Administration}

The highest dose of liraglutide (1.8 mg) was not systematically prescribed in the clinical setting. At baseline, $26.4 \%$ of patients were prescribed a daily dose of $0.6 \mathrm{mg}, 68.3 \%$ prescribed $1.2 \mathrm{mg}$ and $5.3 \%$ prescribed $1.8 \mathrm{mg}$. At 12 months, prescription of $0.6 \mathrm{mg}, 1.2 \mathrm{mg}$ and $1.8 \mathrm{mg}$ was
5.4\%, 58.5\% and 36.1\%, respectively. Regarding concomitant use with other anti-diabetic medication, at baseline, $46.6 \%$ of patients used liraglutide in combination with metformin, $26.5 \%$ with metformin and sulfonylurea, and $5.8 \%$ with basal insulin. In terms of treatment modality, liraglutide was used as an adjunct treatment in $63.2 \%$ of patients, as a switch from a previous drug in $33.4 \%$ and in the context of a reduction in the total number of glucose-lowering drugs in $3.4 \%$ of patients.

\section{Primary and Secondary Outcomes}

During the study, $43.5 \%$ (95\% CI $40.9 ; 46.2)$ of patients attained a reduction in HbA1c of $\geq 1 \%$ point at 12 months (Table 3 ). After 4 months, $44.3 \%(95 \%$ CI $41.8 ; 47.0)$ of patients had a reduction in HbA1c of $\geq 1 \%$ point, $49.6 \%$ (95\% CI $47.0 ; 52.2$ ) of patients attained a reduction in body weight of $\geq 3 \%$, and $26.0 \%$ (95\% CI 23.7 ; 28.4) attained the composite endpoint of both targets. At 24 months, the proportions of 
Table 2 Baseline characteristics

\begin{tabular}{|c|c|c|}
\hline Variable & Sub-variable & Mean \pm SD or $\%$ \\
\hline Patients $(N)$ & & 1723 \\
\hline Age (years) & & $58.9 \pm 9.5$ \\
\hline \multirow[t]{2}{*}{ Sex $(\%)$} & Females & 45.1 \\
\hline & Males & 54.9 \\
\hline Diabetes duration (years) & & $9.6 \pm 7.1$ \\
\hline \multirow[t]{3}{*}{ Categorical diabetes duration (\%) } & $<5$ years & 32.2 \\
\hline & $5-10$ years & 30.7 \\
\hline & $>10$ years & 37.1 \\
\hline \multicolumn{3}{|l|}{ Diabetes complications } \\
\hline Coronary heart disease (\%) & & 13.1 \\
\hline Stroke $(\%)$ & & 1.9 \\
\hline Peripheral vascular disease (\%) & & 6.7 \\
\hline Diabetic retinopathy (\%) & & 18.5 \\
\hline Sensory-motor neuropathy (\%) & & 13.5 \\
\hline Dyslipidemia (\%) & & 65.6 \\
\hline HbAlc (\%) & & $8.3 \pm 1.4$ \\
\hline \multirow[t]{4}{*}{ Categorical HbAlc (\%) } & $\leq 7.5$ & 30 \\
\hline & $7.6-8.0$ & 20.6 \\
\hline & $8.1-8.9$ & 25.9 \\
\hline & $>9.0$ & 23.4 \\
\hline Fasting plasma glucose $(\mathrm{mg} / \mathrm{dl})$ & & $171.8 \pm 52.2$ \\
\hline Body weight $(\mathrm{kg})$ & & $99.6 \pm 18.9$ \\
\hline $\operatorname{BMI}\left(\mathrm{kg} / \mathrm{m}^{2}\right)$ & & $35.6 \pm 5.9$ \\
\hline \multirow[t]{3}{*}{ Categorical BMI (\%) } & $27.1-30 \mathrm{~kg} / \mathrm{m}^{2}$ & 11.9 \\
\hline & $30.1-39.9 \mathrm{~kg} / \mathrm{m}^{2}$ & 61.9 \\
\hline & $\geq 40 \mathrm{~kg} / \mathrm{m}^{2}$ & 21.4 \\
\hline Waist circumference $(\mathrm{cm})$ & & $115.5 \pm 13.4$ \\
\hline Systolic blood pressure $(\mathrm{mmHg})$ & & $139.3 \pm 18.1$ \\
\hline Diastolic blood pressure $(\mathrm{mmHg})$ & & $81.3 \pm 10.0$ \\
\hline Total cholesterol (mg/dl) & & $180.8 \pm 39.8$ \\
\hline HDL cholesterol (mg/dl) & & $45.0 \pm 10.9$ \\
\hline LDL cholesterol $(\mathrm{mg} / \mathrm{dl})$ & & $102.9 \pm 35.3$ \\
\hline Triglycerides (mg/dl) & & $172.0 \pm 90.8$ \\
\hline
\end{tabular}


Table 2 continued

\begin{tabular}{llr}
\hline Variable & Sub-variable & Mean \pm SD or \% \\
\hline Albuminuria $(\mathrm{mg} / \mathrm{l})$ & & $53.2 \pm 123.8$ \\
$\operatorname{eGFR~}\left(\mathrm{ml} / \mathrm{min} / 1.73 \mathrm{~m}^{2}\right)$ & & $85.0 \pm 19.1$ \\
Categorical eGFR $(\%)$ & $\leq 30 \mathrm{ml} / \mathrm{min} / 1.73 \mathrm{~m}^{2}$ & 0.1 \\
& $>30-<60 \mathrm{ml} / \mathrm{min} / 1.73 \mathrm{~m}^{2}$ & 11.4 \\
& $\geq 60-<90 \mathrm{ml} / \mathrm{min} / 1.73 \mathrm{~m}^{2}$ & 43.1 \\
& $\geq 90 \mathrm{ml} / \mathrm{min} / 1.73 \mathrm{~m}^{2}$ & 45.4 \\
\hline
\end{tabular}

BMI body mass index, CKD-EPI Chronic Kidney Disease Epidemiology Collaboration, HbA1c glycated hemoglobin, HDL high-density lipoprotein, $L D L$ low-density lipoprotein, eGFR estimated glomerular filtration rate (using the CKD-EPI formula)

Table 3 Summary of categorical effectiveness endpoints

\begin{tabular}{|c|c|c|c|c|c|c|}
\hline \multirow[t]{2}{*}{ Endpoint } & \multicolumn{2}{|l|}{4 months } & \multicolumn{2}{|l|}{12 months } & \multicolumn{2}{|l|}{24 months } \\
\hline & Frequency & $\%(95 \% \mathrm{CI})$ & Frequency & $\%(95 \% \mathrm{CI})$ & Frequency & $\%(95 \% \mathrm{CI})$ \\
\hline $\begin{array}{l}\text { Patients with } \mathrm{HbAlc} \\
\text { reduction } \geq 1 \% \text { point }\end{array}$ & $620 / 1398$ & $44.3(41.8 ; 47.0)$ & $577 / 1325$ & $43.5(40.9 ; 46.2)$ & $472 / 1136$ & $41.5(38.7 ; 44.4)$ \\
\hline Patients with $\mathrm{HbA} 1 \mathrm{c} \leq 7 \%$ & $645 / 1499$ & $44.5(42.0 ; 47.1)$ & $611 / 1413$ & $44.4(41.8 ; 47.0)$ & $486 / 1217$ & $40.9(38.1 ; 43.7)$ \\
\hline $\begin{array}{l}\text { Patients with weight relative } \\
\text { reduction } \geq 3 \%\end{array}$ & $704 / 1499$ & $49.6(47.0 ; 52.2)$ & $686 / 1413$ & $52.2(49.5 ; 54.9)$ & $608 / 1125$ & $54.0(51.1 ; 56.9)$ \\
\hline $\begin{array}{l}\text { Composite endpoint (i.e., } \\
\text { patients with an HbAlc } \\
\text { reduction } \geq 1 \% \text { point and } \\
\text { weight relative reduction } \\
\geq 3 \%)\end{array}$ & $349 / 1342$ & $26.0(23.7 ; 28.4)$ & $314 / 1256$ & $25.0(22.7 ; 27.5)$ & $274 / 1073$ & $25.5(23.0 ; 28.2)$ \\
\hline
\end{tabular}

$C I$ confidence interval, $H b A l c$ glycated hemoglobin

patients at each endpoint were $41.5 \%$ (95\% CI $38.7 ; 44.4), 54.0 \%$ (95\% CI 51.1; 56.9) and 25.5\% (95\% CI 23.0; 28.2), respectively. Furthermore, at 24 months, 40.9\% (95\% CI 38.1; 43.7) of patients had attained the HbA1c target of $\leq 7 \%$ [16].

Table 4 shows changes in continuous outcomes from baseline to 24 months. At 24 months, mean HbA1c had decreased by $0.8 \%$ (95\% CI - 0.8; - 0.7, p<0.0001), with a reduction of $0.9(95 \% \mathrm{CI}-0.9 ;-0.8)$ at 4 months generally maintained throughout the study (Fig. 1). Mean change in HbA1c from baseline, split by subgroup of concomitant antidiabetic medication, is shown in
Supplementary Figure S1. FPG was reduced by $23.0 \mathrm{mg} / \mathrm{dl}$ (95\% CI - 25.8; - 20.2, $p<0.0001)$.

Improvements in non-glycemic outcomes were also observed following 24 months of treatment with liraglutide. Body weight decreased significantly by $3.4 \mathrm{~kg}$ (95\% CI - 3.6; -3.1 ) and significant reductions were observed in systolic (SBP) and diastolic blood pressure (DBP) $[-3.9 \mathrm{mmHg}(95 \% \mathrm{CI}-5.1$; -2.8$)$ and $-1.9 \mathrm{mmHg}(95 \% \mathrm{CI}-2.5 ;-1.3)$, respectively, both $p<0.0001]$. Regarding the lipid profile, total cholesterol (TC) was reduced by $11.1 \mathrm{mg} /$ dl (95\% CI - 13.5; - 8.8, p<0.0001), low-density lipoprotein (LDL) cholesterol by $11.2 \mathrm{mg} / \mathrm{dl}$ $(95 \% \quad$ CI $\quad-13.5 ; \quad-8.8, \quad p<0.0001) \quad$ and 
Table 4 Changes from baseline to 24 months in continuous outcomes

\begin{tabular}{|c|c|c|c|c|}
\hline Variable & $\begin{array}{l}\text { Baseline (estimated } \\
\text { mean, } 95 \% \mathrm{CI} \text { ) }\end{array}$ & $\begin{array}{l}4 \text { months (estimated } \\
\text { mean change, } 95 \% \mathrm{CI} \text { ) }\end{array}$ & $\begin{array}{l}12 \text { months (estimated } \\
\text { mean change, } 95 \% \mathrm{CI} \text { ) }\end{array}$ & $\begin{array}{l}24 \text { months (estimated } \\
\text { mean change, } 95 \% \mathrm{CI} \text { ) }\end{array}$ \\
\hline HbAlc (\%) & $8.3(8.22 ; 8.34)$ & $-0.9(-0.94 ;-0.78)$ & $-0.8(-0.90 ;-0.75)$ & $-0.8(-0.84 ;-0.72)$ \\
\hline $\begin{array}{l}\text { Fasting } \\
\text { plasma } \\
\text { glucose (\%) }\end{array}$ & $171.9(169.5 ; 174.3)$ & $-23.7(-27.0 ;-20.4)$ & $-24.9(-28.0 ;-21.8)$ & $-23.0(-25.8 ;-20.2)$ \\
\hline $\begin{array}{l}\text { Body weight } \\
\text { (\%) }\end{array}$ & $99.5(98.6 ; 100.4)$ & $-2.8(-3.2 ;-2.4)$ & $-3.3(-3.7 ;-3.0)$ & $-3.4(-3.6 ;-3.1)$ \\
\hline $\begin{array}{l}\text { Systolic } \\
\text { blood } \\
\text { pressure } \\
(\%)\end{array}$ & $138.9(137.9 ; 140.0)$ & $-4.0(-5.39 ;-2.53)$ & $-4.8(-6.14 ;-3.44)$ & $-3.9(-5.0 ;-2.80)$ \\
\hline $\begin{array}{l}\text { Diastolic } \\
\text { blood } \\
\text { pressure } \\
(\%)\end{array}$ & $81.2(80.7 ; 81.8)$ & $-0.9(-1.57 ;-0.14)$ & $-1.3(-2.01 ;-0.64)$ & $-1.9(-2.54 ;-1.30)$ \\
\hline $\begin{array}{l}\text { Total } \\
\text { cholesterol } \\
(\%)\end{array}$ & $180.5(178.2 ; 182.8)$ & $-12.0(-15.2 ;-8.8)$ & $-11.0(-13.9 ;-8.2)$ & $-11.1(-13.5 ;-8.8)$ \\
\hline $\begin{array}{l}\text { HDL } \\
\text { cholesterol } \\
(\%)\end{array}$ & $44.8(44.2 ; 45.4)$ & $-0.6(-1.26 ;-0.09)$ & $0.8(0.23 ; 1.40)$ & $1.3(0.85 ; 1.82)$ \\
\hline $\begin{array}{l}\text { LDL } \\
\text { cholesterol } \\
(\%)\end{array}$ & $103.5(101.5 ; 105.6)$ & $-9.0(-11.81 ;-6.11)$ & $-9.0(-11.64 ;-6.41)$ & $-11.2(-13.49 ;-8.82)$ \\
\hline $\begin{array}{l}\text { Triglycerides } \\
(\%)\end{array}$ & $172.3(167.5 ; 177.2)$ & $-6.0(-12.34 ; 0.27)$ & $-12.7(-18.35 ;-7.00)$ & $-9.4(-14.21 ;-4.49)$ \\
\hline
\end{tabular}

$C I$ confidence interval, $H b A l c$ glycated hemoglobin, $H D L$ high-density lipoprotein, $L D L$ low-density lipoprotein

triglycerides by $9.4 \mathrm{mg} / \mathrm{dl}(95 \% \mathrm{CI}-14.2 ;-4.5$, $p=0.0002$ ). High-density lipoprotein (HDL) cholesterol increased by $1.3 \mathrm{mg} / \mathrm{dl}$ (95\% CI 0.9 ; $1.8, p<0.0001)$. It is important to note that reductions in SBP and LDL cholesterol levels were evident in patients not exposed to antihypertensive or lipid-lowering treatment intensification during the study. Changes in continuous outcomes versus baseline at 4,12 and 24 months, split by prescribed dose, are shown in Supplementary Table S1.

After 24 months, 370 patients $(21.5 \%)$ had discontinued liraglutide. The most common reason for treatment discontinuation, as reported by 45 patients $(2.6 \%)$, was 'intolerance' followed by 'gastrointestinal adverse events', reported in 28 patients (1.6\%).

\section{DISCUSSION}

The ReaL study is the largest observational, noninterventional analysis of liraglutide effectiveness in patients with $\mathrm{T} 2 \mathrm{D}$ in Italian clinical practice. 


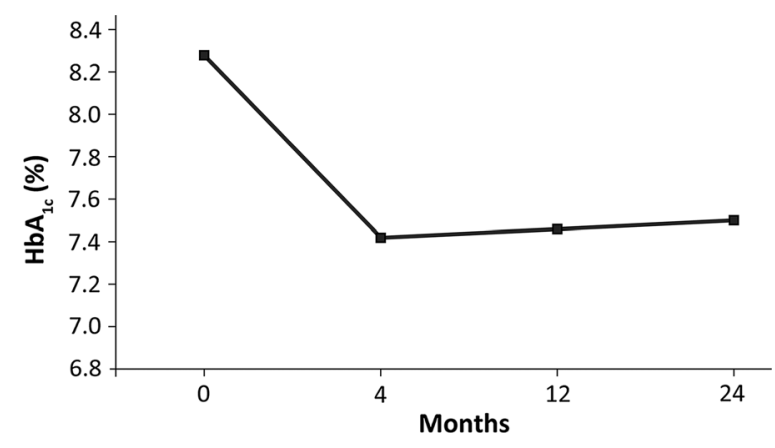

Fig. 1 Mean HbAlc from baseline to 24 months. HbAlc glycated hemoglobin

\section{Patient Characteristics}

Retrospective, consecutive sampling of patients from clinical practice produced a cohort representative of patients routinely prescribed liraglutide. On initiation of liraglutide, mean HbA1c was $8.3 \%$. Mean diabetes duration was around 10 years, and the proportion of patients initiating liraglutide was generally balanced among categories of diabetes duration. Furthermore, mean duration of diabetes was greater than that reported in the LEAD trials, along with BMI and weight. Mean SBP and DBP was 139.3 and $81.3 \mathrm{mmHg}$, respectively; however, at baseline, $60 \%$ of individuals were classed as hypertensive (SBP $140 \mathrm{mmHg}$, DBP $90 \mathrm{mmHg}$ ). Dyslipidemia was present in $65 \%$ of patients prescribed liraglutide at baseline and coronary heart disease present in $13.1 \%$ of patients, while $18.5 \%$ and $13.5 \%$ of patients had been previously diagnosed with diabetic retinopathy and sensory-motor neuropathy, respectively.

\section{Main Findings}

Over $40 \%$ of patients achieved the primary outcome of $\mathrm{a} \geq 1 \%$-point reduction in HbA1c at 12 months, and $40.9 \%$ reached the HbA1c target of $\leq 7.0 \%$. Considering the role of attaining and maintaining the HbA1c target in halting the progression of microvascular diseases, this is an important finding. Comparable results have been observed under similar conditions in several European countries, including Italy [17-19].
A statistically significant reduction in $\mathrm{HbA} 1 \mathrm{c}$ of $0.9 \%$ was observed after 4 months with liraglutide $(p<0.0001)$ and was maintained at both $12(0.8 \%)$ and 24 months (0.8\%), demonstrating encouraging durability with liraglutide under real-life conditions. The reduction in HbA1c at 12 months was smaller than that observed over the same period in the ROOTS [20] study. However, this may be the consequence of the higher baseline HbA1c reported in the ROOTS [20] trial. The mean reduction in HbA1c in this study was similar to that reported in the LEAD studies [8-13] despite differences in study design and the beneficial effects of antidiabetic treatment administered prior to the initiation of liraglutide. Unlike the LEAD trials, in this study approximately one-third of patients were switched to liraglutide from other anti-diabetic drugs, while $3.4 \%$ of patients were prescribed liraglutide in lieu of multiple antidiabetic drugs. This is reflected in the large proportion of patients with an $\mathrm{HbA} 1 \mathrm{c} \leq 7.5 \%$ at baseline (Table 2). Despite a greater baseline duration of diabetes and BMI in the present study, the HbA1c change profile (with an early decrease followed by the leveling off in HbA1c) was comparable to the LEAD trials (Fig. 1).

At 24 months, the proportion of patients with a $\geq 3 \%$ reduction in body weight was $54.0 \%$, with the reduction from baseline being statistically significant. This is consistent with the weight loss observed in the LEAD clinical trials [8-13] and comparable to that reported by other observational trials [20].

\section{Safety and Treatment Discontinuation}

The LEADER trial recently confirmed the cardiovascular safety of liraglutide $1.8 \mathrm{mg}$ in individuals with T2D at increased risk of cardiovascular disease. The primary outcome of first occurrence of death from cardiovascular causes, nonfatal myocardial infarction or nonfatal stroke occurred in fewer patients in the liraglutide group than in the placebo group. Patients on liraglutide were also at lower risk of death from cardiovascular causes and microvascular events [14]. Although safety analyses were not included in this study because of the 
retrospective design, at 24 months significant reductions in SBP, DBP, TC and LDL cholesterol were observed. Furthermore, HDL cholesterol increased significantly from baseline to 24 months. This improvement in blood pressure and lipids, combined with the reductions in weight, supports the findings of the LEADER trial and the positive impact of liraglutide on overall cardiovascular risk. Importantly, around half of the study patients in the current study were prescribed a dose lower than the $1.8 \mathrm{mg}$ dose typically used in the confirmatory clinical trials. By prescribing a lower dose, it is possible that, to some extent, the severity of a number of adverse events associated with liraglutide could be reduced at the expense of the degree of improvements in glycemic control. While this inference is hypothetical and cannot be confirmed by this study, discontinuation in the LEAD trials ranged from $10 \%$ to $25 \%$. However, with the exception of LEAD-3, the final followup in the LEAD trials was 26 weeks [8-13], whereas in this study, at 4 and 12 months, 81 (6.9\%) and 194 (11.3\%) patients had discontinued treatment, respectively. This potentially reflects a greater treatment tolerance, owing to the lower dose. At 24 months, 370 (21.5\%) patients had discontinued treatment with liraglutide. The rate of discontinuation was lower than that reported after 24 months in the EVIDENCE study (36.2\%) [21].

\section{Strengths and Limitations}

The relatively large set of patient records analyzed in this study allowed for greater generalizability of the findings in the target population. Conversely, as the study was retrospective and based on the collection of electronic medical records, the completeness of information depended on the ability of participating centers to record clinical data. It should be noted, however, that the completeness of data was satisfactory, and missing data were accounted for during statistical analysis. However, caution should be applied when evaluating the degree of benefit observed with liraglutide in this study, as there was no control for multiplicity.

\section{CONCLUSIONS}

Two years of treatment with liraglutide in reallife conditions improved HbA1c, body weight, blood pressure and lipids in patients with T2D to a similar extent of that observed in clinical trials. Such improvements were observed despite a wide range of patient characteristics, doses and treatment modalities. Our data support the use of liraglutide as an efficacious treatment for T2D in clinical practice.

\section{ACKNOWLEDGEMENTS}

Funding. The study was supported by Novo Nordisk S.p.A., Rome, Italy, which also funded the article processing charges. All authors had full access to all of the data in this study and take complete responsibility for the integrity of the data and accuracy of the data analysis.

Authorship. All named authors meet the International Committee of Medical Journal Editors (ICMJE) criteria for authorship for this manuscript, take responsibility for the integrity of the work as a whole and accuracy of the data analysis, and have given final approval to the version to be published.

Medical Writing, Editorial, and Other Assistance. The authors acknowledge Istituto di Ricerche Farmacologiche Mario Negri (Milan, Italy), responsible for data management; CORESEARCH-Center for Outcomes Research and Clinical Epidemiology (Pescara, Italy), responsible for statistical analysis; TFS People (Rome, Italy), responsible for submission to Independent Ethics Committees, study closure procedures, creation and delivery of study files; and the trial personnel and participants for their commitment and involvement. The authors thank Margit Kaltoft for her input (Novo Nordisk) and Jamie Cozens, MSc, of Watermeadow Medical, an Ashfield Company, for editorial assistance (supported by Novo Nordisk).

Disclosures. Lapolla A: investigator in clinical trials sponsored by Novo Nordisk, Lilly, 
Boehringer Ingelheim and Sanofi. Berra C: consulting fees from Novo Nordisk, Lilly, Boehringer Ingelheim, Sanofi, Johnson \& Johnson and Bayer; research support from AstraZeneca and Takeda; member of advisory boards for Novo Nordisk, Lilly, Boehringer Ingelheim, AstraZeneca and Sanofi; investigator in clinical trials sponsored by Lilly and Sanofi. Boemi M: member of advisory boards for Lilly, Boehringer Ingelheim and Sanofi; investigator in clinical trials sponsored by Novo Nordisk, Boehringer Ingelheim and Merck SD. Bossi AC: investigator in clinical trials sponsored by Novo Nordisk, Lilly, Bayer and Sanofi; consulting fees from AstraZeneca, Roche, Johnson \& Johnson and Takeda; research support from Merck SD and Sigma Tau; member of advisory board for Boehringer Ingelheim. Candido R: investigator in clinical trials sponsored by Novo Nordisk, Lilly and Merck SD; consulting fees from AstraZeneca, Roche and Johnson \& Johnson; member of advisory board for Boehringer Ingelheim. Di Cianni G: investigator in clinical trials sponsored by Novo Nordisk, AstraZeneca and Sanofi; member of advisory boards for Lilly and Sanofi. Frontoni S: member of advisory boards for Novo Nordisk, Lilly, AstraZeneca, Johnson \& Johnson, Takeda and Sigma Tau; investigator in clinical trials sponsored by Novo Nordisk and Boehringer Ingelheim. Genovese S: consulting fees from Novo Nordisk, Lilly, Boehringer Ingelheim, AstraZeneca, Merck SD, Sanofi, Johnson \& Johnson, Takeda, Abbott Diabetes Care, Bristol Myers \& Squibb, Janssen, Lifescan, Menarini and Novartis; member of advisory boards for Novo Nordisk, Boehringer Ingelheim, AstraZeneca, Merck SD, Sanofi, Johnson \& Johnson, Takeda, Abbott Diabetes Care, Bruno Farmaceutici, Janssen, Lifescan and Novartis; research support from Novartis; investigator in clinical trials sponsored by Novo Nordisk, Lilly, Boehringer Ingelheim, AstraZeneca, Merck SD, Takeda, Janssen and Novartis. Ponzani P: investigator in clinical trials sponsored by Boehringer Ingelheim, Sanofi, Johnson \& Johnson, Bayer and Novartis; member of advisory boards for Novo Nordisk and AstraZeneca. Provenzano V: consulting fees from Novo Nordisk, Lilly, Boehringer Ingelheim, AstraZeneca, Merck SD, Sanofi and Takeda; member of advisory boards for Novo Nordisk, Lilly, Boehringer Ingelheim, AstraZeneca and Sanofi; investigator in clinical trials sponsored by Novo Nordisk, Lilly, Boehringer Ingelheim, AstraZeneca, Merck SD, Sanofi and Roche. Russo GT: investigator in clinical trials sponsored by Lilly, Boehringer Ingelheim, Merck SD, Sanofi and Johnson \& Johnson; member of advisory boards for Novo Nordisk, Lilly and Boehringer Ingelheim, member of advisory boards for, and consulting fees from, Novo Nordisk, Lilly and Boehringer Ingelheim. Sciangula L: member of advisory boards for Novo Nordisk, Lilly, AstraZeneca and Johnson \& Johnson; consulting fees from Roche; investigator in clinical trials sponsored by Novo Nordisk. Simioni N: Consulting fees from Novo Nordisk, Lilly, Boehringer Ingelheim and Abbott; member of advisory boards for Novo Nordisk, Lilly and Boehringer Ingelheim; investigator in clinical trials sponsored by Novo Nordisk. Bette C: employee of Novo Nordisk SpA (Rome, Italy). Nicolucci A: consulting fees from Novo Nordisk, Lilly, AstraZeneca, Sanofi and Medtronic; research support from Novo Nordisk, Sigma Tau, Dexcom and Artsana; member of advisory boards for Novo Nordisk and AstraZeneca.

Compliance with Ethics Guidelines. All procedures followed were in accordance with the ethical standards of the responsible committee on human experimentation (institutional and national) and with the Helsinki Declaration of 1964, as revised in 2013. Informed consent was obtained from all patients before being included in the study.

Data Availability. The data sets during and/ or analyzed during the current study are available from the corresponding author on reasonable request.

Open Access. This article is distributed under the terms of the Creative Commons Attribution-NonCommercial 4.0 International License (http://creativecommons.org/licenses/ by-nc/4.0/), which permits any noncommercial use, distribution, and reproduction in any medium, provided you give appropriate credit to the original author(s) and the source, provide 
a link to the Creative Commons license, and indicate if changes were made.

\section{REFERENCES}

1. Inzucchi SE, Bergenstal RM, Buse JB, et al. Management of hyperglycemia in type 2 diabetes: a patient-centered approach: position statement of the American Diabetes Association (ADA) and the European Association for the Study of Diabetes (EASD). Diabetes Care. 2012;35:1364-79.

2. Inzucchi SE, Bergenstal RM, Buse JB, et al. Management of hyperglycemia in type 2 diabetes, 2015: a patient-centered approach: update to a position statement of the American Diabetes Association and the European Association for the Study of Diabetes. Diabetes Care. 2015;38:140-9.

3. Hankinson AL. Epidemiologic and pathophysiologic links between obesity and hypertension. Curr Cardiovasc Risk Reps. 2009;3:264-71.

4. World Health Organization. Global strategy on diet, physical activity and health: obesity and overweight. 2017. http://www.who.int/ dietphysicalactivity/media/en/gsfs_obesity.pdf. Accessed 27 Sept 2017.

5. Meier JJ. GLP-1 receptor agonists for individualized treatment of type 2 diabetes mellitus. Nat Rev Endocrinol. 2012;8:728-42.

6. Novo Nordisk. Victoza $6 \mathrm{mg} / \mathrm{ml}$ solution for injection in pre-filled pen SmPC. 2017. https://www. medicines.org.uk/emc/medicine/21986. Accessed 1 Sept 2017.

7. Marathe PH, Gao HX, Close KL. American Diabetes Association standards of medical care in diabetes 2017. J Diabetes. 2017;9:320-4.

8. Buse JB, Rosenstock J, Sesti G, et al. Liraglutide once a day versus exenatide twice a day for type 2 diabetes: a 26-week randomised, parallel-group, multinational, open-label trial (LEAD-6). Lancet. 2009;374:39-47.

9. Garber A, Henry R, Ratner R, et al. Liraglutide versus glimepiride monotherapy for type 2 diabetes (LEAD-3 Mono): a randomised, 52-week, phase III, double-blind, parallel-treatment trial. Lancet. 2009;373:473-81.

10. Marre M, Shaw J, Brandle $M$, et al. Liraglutide, a once-daily human GLP-1 analogue, added to a sulphonylurea over 26 weeks produces greater improvements in glycaemic and weight control compared with adding rosiglitazone or placebo in subjects with type 2 diabetes (LEAD-1 SU). Diabet Med. 2009;26:268-78.

11. Nauck M, Frid A, Hermansen K, et al. Efficacy and safety comparison of liraglutide, glimepiride, and placebo, all in combination with metformin, in type 2 diabetes: the LEAD (liraglutide effect and action in diabetes)-2 study. Diabetes Care. 2009;32:84-90.

12. Russell-Jones D, Vaag A, Schmitz O, et al. Liraglutide vs insulin glargine and placebo in combination with metformin and sulfonylurea therapy in type 2 diabetes mellitus (LEAD-5 met $+\mathrm{SU}$ ): a randomised controlled trial. Diabetologia. 2009;52:2046-55.

13. Zinman B, Gerich J, Buse JB, et al. Efficacy and safety of the human glucagon-like peptide- 1 analog liraglutide in combination with metformin and thiazolidinedione in patients with type 2 diabetes (LEAD-4 Met+ TZD). Diabetes Care. 2009;32:1224-30.

14. Marso SP, Daniels GH, Brown-Frandsen $\mathrm{K}$, et al. Liraglutide and cardiovascular outcomes in type 2 diabetes. N Engl J Med. 2016;375:311-22.

15. Ostawal A, Mocevic E, Kragh N, Xu W. Clinical effectiveness of liraglutide in type 2 diabetes treatment in the real-world setting: a systematic literature review. Diabetes Ther. 2016;7:411-38.

16. Diabetologia SID. Standard Italiani Per La Cura Del Diabete Mellito. 2010. http://www.aemmedi.it/ files/Linee-guida_Raccomandazioni/2010/20102010_linee_guida.pdf. Accessed 27 Sept 2017.

17. Fadini GP, Simioni N, Frison V, et al. Independent glucose and weight-reducing effects of Liraglutide in a real-world population of type 2 diabetic outpatients. Acta Diabetol. 2013;50:943-9.

18. Lapolla A, Frison V, Bettio M, et al. Correlation between baseline characteristics and clinical outcomes in a large population of diabetes patients treated with liraglutide in a real-world setting in Italy. Clin Ther. 2015;37:574-84.

19. Ponzani P. Long-term effectiveness and safety of liraglutide in clinical practice. Minerva Endocrinol. 2013;38:103-12.

20. Buysschaert $M, D^{\prime}$ Hooge $D$, Preumont V, Roots Study G. ROOTS: a multicenter study in Belgium to evaluate the effectiveness and safety of liraglutide $\left(\right.$ Victoza $\left.^{\circledR}\right)$ in type 2 diabetic patients. Diabetes Metab Syndr. 2015;9:139-42.

21. Gautier JF, Martinez L, Penfornis A, et al. Effectiveness and persistence with liraglutide among patients with type 2 diabetes in routine clinical practice-EVIDENCE: a prospective, 2-year follow-up, observational, post-marketing study. Adv Ther. 2015;32:838-53. 